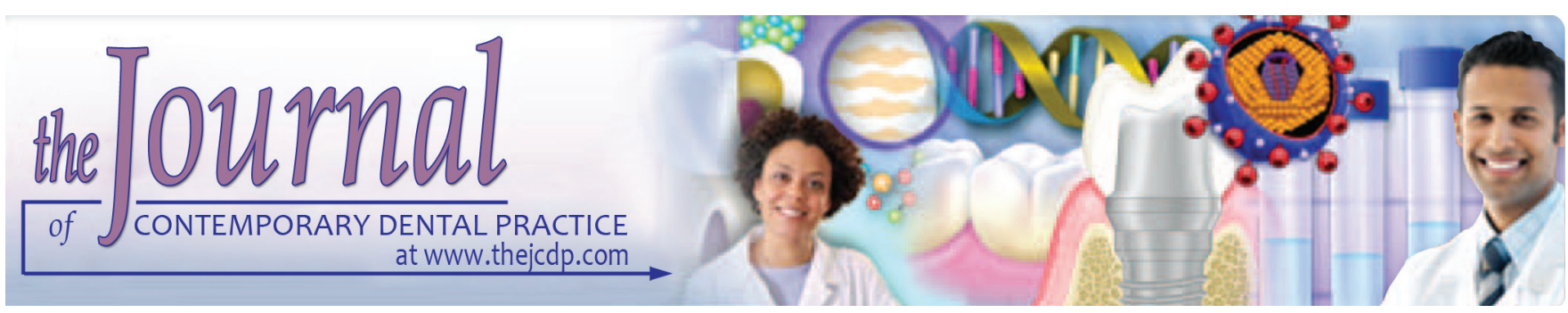

\title{
Antibacterial Effect of Silver Diamine Fluoride on Cariogenic Organisms
}

\author{
${ }^{1}$ Yali Lou, ${ }^{2}$ Brain W Darvell, ${ }^{3}$ Michael G Botelho
}

\begin{abstract}
Aim: To screen the possible antimicrobial activity of a range of clinically used, silver-based compounds on cariogenic organisms: silver diamine fluoride (SDF), silver fluoride, and silver nitrate.

Materials and methods: Preliminary screening disk-diffusion susceptibility tests were conducted on Mueller-Hinton agar plates inoculated with Streptococcus mutans, Lactobacillus acidophilus, and Actinomyces naes/undii, organisms known to be cariogenic. In order to identify which component of the silver compounds was responsible for any antibacterial (AB) effect, and to provide controls, the following were also investigated at high and low concentrations: sodium fluoride, ammonium fluoride, ammonium chloride, sodium fluoride, sodium chloride, and sodium nitrate, as well as deionized water as control. A volume of $10 \mu \mathrm{L}$ of a test solution was dispensed onto a paper disk resting on the inoculated agar surface, and the plate incubated anaerobically at $37^{\circ} \mathrm{C}$ for 48 hours. The zones of inhibition were then measured.
\end{abstract}

Results: Silver diamine fluoride, silver fluoride, silver nitrate, and ammonium fluoride had significant $A B$ effect $(p<0.05)$ on all three test organisms, although ammonium fluoride had no effect at low concentration; the remaining other compounds had no effect.

Conclusion: Silver ions appear to be the principal $A B$ agent at both high and low concentration; fluoride ions only have an $A B$ effect at high concentration, while ammonium, nitrate, chloride

\footnotetext{
${ }^{1}$ Department of Neurology, Brigham \& Women's Hospital Boston, Massachusetts, USA

${ }^{2}$ Dental Materials Science, School of Dentistry, University of Birmingham, Birmingham, UK

${ }^{3}$ Department of Prosthodontics, Faculty of Dentistry, University of Hong Kong Prince Philip Dental Hospital, Sai Ying Pun, Hong Kong, China

Corresponding Author: Michael G Botelho, Department of Prosthodontics, Faculty of Dentistry, University of Hong Kong Prince Philip Dental Hospital, Sai Ying Pun, Hong Kong, China e-mail: botelho@hku.hk
}

and sodium ions have none. The anticaries effect of topical silver solutions appears restricted to that of the silver ions.

Clinical significance: Silver compounds, such as SDF, silver fluoride, and silver nitrate have $A B$ effect against cariogenic organisms and these may have clinical impact in arresting or preventing dental decay. Sodium fluoride did not have AB effect under the conditions tested.

Keywords: Agar diffusion test, Ammonium fluoride, Antibacterial, Caries, Fluoride, Silver diamine fluoride, Silver nitrate.

How to cite this article: Lou Y, Darvell BW, Botelho MG. Antibacterial Effect of Silver Diamine Fluoride on Cariogenic Organisms. J Contemp Dent Pract 2018;19(5):591-598.

Source of support: This work was done in partial fulfillment of the requirements for the degree of PhD for YaLi Lou at and supported by the Faculty of Dentistry, the University of Hong Kong.

\section{Conflict of interest: None}

\section{INTRODUCTION}

The effect of silver as an AB agent for public health care, such as for water or milk storage and water purification, has been known for centuries. ${ }^{1}$ This beneficial effect has been used in many other contexts, including soft tissue wound care, ${ }^{2}$ bone prostheses, reconstructive orthopedic surgery, ${ }^{3}$ cardiac devices, ${ }^{4}$ catheters and surgical appliances, ${ }^{5}$ as well in the form of ionizable silver in fabrics for clinical use (to reduce the risk of nosocomial infections) and personal hygiene products. ${ }^{1,6,7} \mathrm{New}$ commercial contexts continue to be found and promoted.

The $A B$ effect of silver has been suggested to have three possible mechanisms:

1. Prevention of cellular respiration: Silver ions are thought to bind nonspecifically to bacterial cell surfaces, causing disruption of membrane transport functions; this disruption then allows silver ions to penetrate the microbe..$^{8,9}$

2. Inhibition of cell division (reproduction): Silver ions react with the base pairs of deoxyribonucleic acid, thus preventing replication. ${ }^{9-11}$ 
3. Disruption of cell metabolism: Silver ions are highly reactive and readily bind to thiol groups $(\mathrm{SH})$ which are present in enzymes, denaturing them. The energy system of the organism is thereby incapacitated, osmotic pressure cannot be maintained, and this leads to vital substrate leakage, causing death. ${ }^{1,12,13}$

These are clearly not mutually exclusive. Indeed, other more general effects are anticipated because $\mathrm{Ag}^{+}$ is a strong oxidizing agent, reacting with many organic compounds and materials.

Lansdown and Williams ${ }^{3}$ have given a comprehensive account of the use of silver in health-related contexts, but offer no indication of when it was introduced to dentistry as such. It has been claimed that the value of silver nitrate was recognized in $1846,{ }^{14}$ but no source was given for this. The first clear report of clinical observations following the treatment of caries with silver nitrate appears to be from $1891 .^{15}$ Miller investigated the action of silver nitrate on "ivory" and claimed that it may be protective by forming a barrier in the surface of the dentin. ${ }^{16}$ The addition of ammonium hydroxide to a silver nitrate solution $^{17}$ converts the acidic, irritating solution (salt of weak base and strong acid) to an alkaline one said to give little or no irritation to the pulp. ${ }^{14}$ While numerous investigations have reported on its disinfectant effect, ${ }^{18-22}$ its use was questioned for its potentially injurious action on the contents of vital dentinal tubules and odontoblasts as well as the pulp. ${ }^{23}$ It is said to be have become unpopular in medical health care due to the irremovable black stain that it causes, and the emergence of antibiotics appeared to make it redundant. ${ }^{24}$

It has been claimed that silver and fluoride ions together have a better anticaries effect than either silver nitrate or sodium fluoride alone. ${ }^{25}$ It was then suggested that $\mathrm{SDF}^{26}$ might react with the tooth mineral hydroxyapatite to form calcium fluoride and silver phosphate, which was thought to be responsible for the prevention of dental caries and the hardening of existing lesions. ${ }^{27}$ A simplified chemical reaction scheme was suggested:

$$
\mathrm{Ca}_{10}\left(\mathrm{PO}_{4}\right)_{6}(\mathrm{OH})_{2}+\mathrm{Ag}\left(\mathrm{NH}_{3}\right)_{2} \mathrm{~F} \rightarrow \mathrm{CaF}_{2}+\mathrm{Ag}_{3} \mathrm{PO}_{4}+\mathrm{NH}_{4} \mathrm{OH}
$$

X-ray diffraction was used to support the conclusion that calcium fluoride $\left(\mathrm{CaF}_{2}\right)$ and silver phosphate $\left(\mathrm{Ag}_{3} \mathrm{PO}_{4}\right)$ are the major products of reaction with $\mathrm{SDF}^{28,29}$ However, the relative roles of silver and fluoride were not determined, and it is not clear whether the fluoride as such improves the anticaries effect in a direct AB. For example, Klein et al $^{30}$ studied a bacterial model system to compare four agents in respect of their abilities to inhibit carious lesion progression in enamel. They found that both silver fluoride $(\mathrm{AgF})+$ stannous fluoride $\left(\mathrm{SnF}_{2}\right)$ and silver nitrate $\left(\mathrm{AgNO}_{3}\right)$ alone significantly decreased caries progression better than did either SDF or chlorhexidine.
Other clinical investigations have shown the beneficial use of SDF in arresting enamel and dentin caries in children in vivo. ${ }^{31-33}$ However, laboratory studies have all been on sound or demineralized permanent dentition enamel, while the clinical studies have been on the primary dentition. Thus, although no distinction is expected, the absence of a direct demonstration of equivalence leaves some doubt about comparability. Subsequently, using the agar-diffusion method and serial dilution, both 12 and 30\% SDF were found to have $A B$ activity in buccal swab cultures from both high and low caries risk pediatric patients. ${ }^{34}$

The reaction of SDF and $\mathrm{AgNO}_{3}$ with tooth tissue components has been studied further. ${ }^{35}$ SDF produced globular particles of $\mathrm{CaF}_{2}$ on the surface of hydroxyapatite, but these disappeared on washing. With $\mathrm{AgNO}_{3}$, $\mathrm{Ag}_{3} \mathrm{PO}_{4}$ crystals were formed which were not dissolved on washing, but which darkened, converting gradually to metallic silver, on exposure to light. On gelatin, both $\mathrm{SDF}$ and $\mathrm{AgNO}_{3}$ produced particles of silver which were resistant to washing.

Despite the evident importance, very little specific work relevant to the subject has been reported in the last 50 years. Thus, given the lack of explicit mechanism for the effect of SDF, the aim of the present study was to determine the relative $\mathrm{AB}$ effects on cariogenic organisms of silver and fluoride ions in silver- and fluoride-based agents used in dentistry by means of diffusion-gradient sensitivity testing, i.e., using the disk-diffusion susceptibility test, also known as the agar diffusion test (ADT), ${ }^{36}$ which is simple, fast, and reliable. ${ }^{37}$ This was to ascertain whether more elaborate testing would be appropriate.

\section{MATERIALS AND METHODS}

\section{Test Principle}

Since organisms must vary in their sensitivity to agents, testing by means of serial dilution in culture media, while feasible, is of low resolution and inefficient. Utilizing the continuity of a diffusion gradient from a high concentration source, the location of the inhibition concentration is automatically identified and the distance from the source can be used as a proxy for sensitivity, narrowing the range required for any subsequent work.

\section{Test Agents}

Stock solutions were prepared of each agent and of several control compounds with ions in common in a combinatorial scheme (Table 1). Thus, $\mathrm{Ag}\left(\mathrm{NH}_{3}\right)_{2} \mathrm{~F}$ (SDF) (J. Morita Corporation, Osaka, Japan), silver fluoride (AgF), silver nitrate $\left(\mathrm{AgNO}_{3}\right)$, ammonium chloride $\left(\mathrm{NH}_{4} \mathrm{Cl}\right)$, ammonium fluoride $\left(\mathrm{NH}_{4} \mathrm{~F}\right)$, sodium chloride $(\mathrm{NaCl})$, sodium fluoride $(\mathrm{NaF})$, and sodium nitrate $\left(\mathrm{NaNO}_{3}\right)($ all Sigma Chemical, St. 
Antibacterial Effect of Silver Diamine Fluoride

Table 1: Test solutions. For $\mathrm{NH}_{4} \mathrm{~F}, 100$ and $200 \mathrm{mg} \mathrm{mL}^{-1}$ were also tested

\begin{tabular}{|c|c|c|c|c|c|c|c|c|}
\hline \multirow[b]{2}{*}{ Agent } & \multicolumn{4}{|c|}{ High concentration } & \multicolumn{4}{|c|}{ Low concentration } \\
\hline & $m g m L^{-1}$ & $m o l L^{-1}$ & {$[F] / p p m$} & $p H$ & $m g m L^{-1}$ & $m o l L^{-1}$ & {$[F] / p p m$} & $p H$ \\
\hline SDF & 380 & 2.36 & 38,021 & 12.5 & 40 & 0.25 & 4,000 & 12.0 \\
\hline $\mathrm{AgNO}_{3}$ & 380 & 2.24 & - & 5.5 & 40 & 0.24 & - & 7.0 \\
\hline $\mathrm{AgF}$ & 380 & 3.00 & 53,858 & 12.5 & 40 & 0.32 & 5,670 & 12.0 \\
\hline $\mathrm{NH}_{4} \mathrm{Cl}$ & $330^{*}$ & & - & 6.0 & 40 & & - & 7.0 \\
\hline $\mathrm{NH}_{4} \mathrm{~F}$ & 400 & & 194,594 & 7.0 & 40 & & 19,459 & 7.0 \\
\hline $\mathrm{NaF}$ & $-^{*}$ & & - & $-^{*}$ & 40 & & 17,143 & 10.5 \\
\hline $\mathrm{NaCl}$ & 400 & & - & 7.0 & 40 & & - & 7.0 \\
\hline $\mathrm{NaNO}_{3}$ & $220^{*}$ & & - & 8.0 & 40 & & - & 7.0 \\
\hline
\end{tabular}

*Due to limited solubility, high concentration was not possible for $\mathrm{NaF}$, and only limited values for $\mathrm{NH}_{4} \mathrm{Cl}$ and $\mathrm{NaNO}_{3}$

Louis, Missouri, USA) were dissolved in deionized water (Milli-Q Plus, Millipore, Billerica, Massachusetts, USA) at two concentrations. To avoid adventitious organisms which might interfere with the analysis, all solutions were filtered using a nonpyrogenic, sterile, single-use syringe filter (0.2 um Super Membrane Acrodisc, Millex-GS, Millipore, France). Deionized water was used as a negative control. Approximate $\mathrm{pH}$ values were estimated using $\mathrm{pH}$ paper (Macherey-Nagel, Germany), pH electrodes being compromised by some of the test solutions.

Due to the very large $\mathrm{AB}$ effect subsequently found for $400 \mathrm{mg} / \mathrm{mL} \mathrm{NH}_{4} \mathrm{~F}$ solution, additional concentrations of 100 and $200 \mathrm{mg} / \mathrm{mL}$ were also tested in the same way for this agent.

\section{Bacteria}

Inocula of S. mutans [American Type Culture Collection (ATCC) 35668], L. acidophilus (ATCC 9224), and A. naeslundii (ATCC 12104), some of the main organisms known to be involved in the caries process, were prepared from a 24-hour anaerobic incubation on blood-agar. Organisms were harvested to produce suspensions in sterile brainheart infusion media (Oxoid, Unipath, Basingstoke, England) to a MacFarland optical density of 0.5 at $660 \mathrm{~nm}$.

\section{Preparation, Incubation, and Reading of Agar Diffusion Plates}

For each suspension, $20 \mu \mathrm{L}$ was dispersed onto a MuellerHinton agar plate ( $\mathrm{pH} 7$, Oxoid) using the lawn-deposition mode of a spiral plater programmed to give a uniform bacterial coverage (Autoplate 4000, Spiral Biotech, Norwood, Massachusetts USA). All plates were prepared on the same day. Ten minutes after plating, $10 \mu \mathrm{L}$ portions of the test solutions were applied to filter paper disks $(6 \mathrm{~mm}$ diameter, Macherey-Nagel) which had been placed on the agar. After 48-hour anaerobic incubation of the plates, inverted, at $37^{\circ} \mathrm{C}$, the diameter of the zone of inhibition around each disk was measured with a Vernier caliper to the nearest half-millimeter. The area of inhibition was then calculated since the diffused concentration is expected to fall with the square of the radius and thus balance the weighting of results for larger diameters. The area of the filter paper disk $\left(28 \mathrm{~mm}^{2}\right)$ was ignored, treating a diameter of $6 \mathrm{~mm}$ as zero. All trials were conducted with ten replicates. In the event of a filter paper disk separating from the agar, the data were dropped. To minimize variation, all plates were prepared in one session at a controlled temperature $\left(25^{\circ} \mathrm{C}\right)$, with constant agar volume..$^{38,39}$

\section{Statistical Analysis}

Statistical tests were conducted in software (Statistical Package for the Social Sciences for Windows, version 15, SPSS, Chicago, Illinois, USA). Three-way analysis of variance (agent $\times$ concentration $\times$ species) $(\mathrm{AoV})$ was followed by lower level tests as indicated by the results, applying Bonferroni protection as appropriate in post hoc multiple comparisons. The significance cut-off was set at $\alpha=0.05$.

\section{RESULTS}

The three-way AoV indicated highly significant effects for all three main factors as well as all interactions $(\mathrm{p}<0.001)$. Accordingly, the design was broken down to separate high- and low-concentration results.

\section{High Concentration}

Two-way AoV (agent $\times$ species) showed that $A$. naeslundii was significantly more sensitive than $S$. mutans $(\mathrm{p}<0.001)$, itself significantly more sensitive than $L$. acidophilus $(\mathrm{p}<0.001)$. However, the interaction was significant $(\mathrm{p}<0.001)$.

The inhibition zone areas are shown in Graph 1, and the numerical comparisons in Table 2. For all silver compounds, a circular black zone of reduced silver was formed around the paper disk; this was always of a smaller diameter than the inhibition zone. $\mathrm{AgF}, \mathrm{AgNO}_{3}$, $\mathrm{SDF}$, and $\mathrm{NH}_{4} \mathrm{~F}$ had significant bacterial inhibition ( $p<0.001$ ), while $\mathrm{NH}_{4} \mathrm{Cl}, \mathrm{NaCl}$, and $\mathrm{NaNO}_{3}$ did not show any such effect. The $\mathrm{AB}$ effect of $\mathrm{NH}_{4} \mathrm{~F}$ (at high concentration) was significantly greater than for all other agents for S. mutans and A. naeslundii, while for L. acidophilus, $\mathrm{NH}_{4} \mathrm{~F}$ 
Table 2: Inhibition zone area (mean $\pm \mathrm{SD}, \mathrm{mm}^{2}$ ) of $S$. mutans, A. naeslundii, and $L$. acidophilus for high concentration tests (Table 1 )

\begin{tabular}{llll}
\hline & S. mutans & A. naes/undii & L. acidophilus \\
\hline $\mathrm{SDF}$ & $395.8 \pm 15.1^{\mathrm{a}}$ & $386.1 \pm 44.1^{\mathrm{a}}$ & $362.6 \pm 23.7^{\mathrm{a}}$ \\
$\mathrm{AgF}$ & $423.6 \pm 82.4^{\mathrm{a}}$ & $528.9 \pm 50.3^{\mathrm{a}}$ & $208.7 \pm 13.9^{\mathrm{b}}$ \\
$\mathrm{AgNO}_{3}$ & $177.8 \pm 14.9^{\mathrm{b}}$ & $225.4 \pm 47.4^{\mathrm{b}}$ & $171.2 \pm 20.8^{\mathrm{b}}$ \\
$\mathrm{NH}_{4} \mathrm{~F}$ & $1666 \pm 174^{\mathrm{c}}$ & $1437 \pm 270^{\mathrm{c}}$ & $437 \pm 121^{\mathrm{a}}$ \\
$\mathrm{NH}_{4} \mathrm{Cl}$ & $0^{\mathrm{d}}$ & $0^{\mathrm{d}}$ & $0^{\mathrm{c}}$ \\
$\mathrm{NaF}$ & - & - & - \\
$\mathrm{NaCl}$ & $0^{\mathrm{d}}$ & $0^{\mathrm{d}}$ & $0^{\mathrm{c}}$ \\
$\mathrm{NaNO}_{3}$ & $0^{\mathrm{d}}$ & $0^{\mathrm{d}}$ & $0^{\mathrm{c}}$ \\
Deionized water & $0^{\mathrm{d}}$ & $0^{\mathrm{d}}$ & $0^{\mathrm{c}}$ \\
\hline
\end{tabular}

Within species, values with the same letter are not significantly different from each other $(p>0.05)$. Others are significantly different at $p<0.005$; SD: Standard deviation

and SDF were significantly more effective than other agents, but with no significant difference between them. The edge of the inhibition zone for $\mathrm{NH}_{4} \mathrm{~F}$ to $S$. mutans, $A$. naeslundii, and L. acidophilus was obscure whilst that for silver compounds was very sharp.

\section{Low Concentration}

The two-way AoV as above showed no significant sensitivity difference between $A$. naeslundii and S. mutans ( $p>0.05)$, although both were significantly more sensitive than L. acidophilus $(\mathrm{p}<0.001)$. Again, there was a significant interaction $(\mathrm{p}<0.001)$.

Again, for all silver compounds, a circular black zone of reduced silver was formed around the paper disk, again, smaller than the inhibition zone. The numerical comparisons are in Table 3. $\mathrm{AgF}, \mathrm{AgNO}_{3}$, and SDF showed significant bacterial inhibition compared with the other test agents $(\mathrm{p}<0.001)$. Although $\mathrm{NH}_{4} \mathrm{~F}$ showed a high $\mathrm{AB}$ effect at high concentration, none was shown at low concentration. This was investigated further.

\section{Ammonium Fluoride}

There was no effect for any species at a concentration $\leq$ $100 \mathrm{mg} / \mathrm{mL}$. The results for $200 \mathrm{mg} / \mathrm{mL}$ are shown in

Table 3: Inhibition zone area (mean $\pm \mathrm{SD}, \mathrm{mm}^{2}$ ) of $S$. mutans, $A$. naeslundii, and $L$. acidophilus for low concentration tests (Table 1)

\begin{tabular}{llll}
\hline & S. mutans & A. naeslundii & L. acidophilus \\
\hline $\mathrm{SDF}$ & $229.9 \pm 24.0^{\mathrm{a}}$ & $199.1 \pm 6.1^{\mathrm{a}}$ & $142.2 \pm 40.3^{\mathrm{a}}$ \\
$\mathrm{AgF}$ & $217.3 \pm 18.7^{\mathrm{a}}$ & $217.3 \pm 18.7^{\mathrm{a}}$ & $81.2 \pm 4.7^{\mathrm{b}}$ \\
$\mathrm{AgNO}_{3}$ & $213.2 \pm 22.7^{\mathrm{a}}$ & $199.8 \pm 18.4^{\mathrm{a}}$ & $155.4 \pm 23.5^{\mathrm{a}}$ \\
$\mathrm{NH}_{4} \mathrm{~F}$ & $0^{\mathrm{b}}$ & $0^{\mathrm{b}}$ & $0^{\mathrm{c}}$ \\
$\mathrm{NH}_{4} \mathrm{Cl}$ & $0^{\mathrm{b}}$ & $0^{\mathrm{b}}$ & $0^{\mathrm{c}}$ \\
$\mathrm{NaF}$ & $0^{\mathrm{b}}$ & $0^{\mathrm{b}}$ & $0^{\mathrm{c}}$ \\
$\mathrm{NaCl}$ & $0^{\mathrm{b}}$ & $0^{\mathrm{b}}$ & $0^{\mathrm{c}}$ \\
$\mathrm{NaNO}_{3}$ & $0^{\mathrm{b}}$ & $0^{\mathrm{b}}$ & $0^{\mathrm{c}}$ \\
Deionized water & $0^{\mathrm{b}}$ & $0^{\mathrm{b}}$ & $0^{\mathrm{c}}$
\end{tabular}

Within species, values with the same letter are not significantly different from each other $(p>0.05)$. Others are significantly different at $p<0.005$; SD: Standard deviation
Graphs 1A and B as for medium concentration. Two-way AoV (species $\times$ concentration) showed a clear effect for both factors $(p<0.001)$, as well as significant interaction $(\mathrm{p}<0.001)$. Again, there was no significant difference between $S$. mutans and A. naeslundii ( $\mathrm{p}>0.05)$; both showed a clear dose effect (multiple comparison test, $\mathrm{p}<0.001$ ). Lactobacillus acidophilus was less sensitive than the other two $(\mathrm{p}<0.001)$, there being no $\mathrm{AB}$ effect at $200 \mathrm{mg} / \mathrm{mL}$.

\section{DISCUSSION}

In the mouth, bacteria grow in complex biofilms. ${ }^{38,39}$ Hence, the use of an oral biofilm model might be considered a more appropriate means of simulating the oral environment for assessing $\mathrm{AB}$ agents. ${ }^{40}$ However, the creation of such a model or chemostat is complex, expensive, and time consuming. A preliminary in vitro assessment is therefore, valuable to determine whether further investigation is warranted. The ADT is the generally accepted procedure for determining in vitro sensitivity under routine laboratory conditions. ${ }^{39}$ An ADT is simple to perform, relatively reproducible, direct, well-controlled, and allows bacteria to grow in a simple biofilm on the agar surface. Results can be obtained in a short period of time. Nevertheless, it is recognized that the ADT does not simulate the clinical environment, and further work would follow for a detailed understanding.

It can be noted that the concentrations used in the paper disk are necessarily high, and may well be far higher than would be feasible in a treatment context, simply to provide a large enough gradient and an inhibition zone that can be measured with sufficient resolution to be discriminatory. It is also true that both $\mathrm{pH}$ and osmotic effects could be involved. However, these effects will be present anyway should such agents be used in practice, and still have the relevant gradients in the test medium. To disentangle these factors would require much more complex experimentation, but in the absence of information to the effect that adjustment to either is appropriate for better efficacy (with otherwise benign species, but noting that osmolarity cannot be reduced independently), all that can be done is to test each agent as-is, as used clinically. "Adjuvants" would have to be explored separately.

In view of the possibility of confounding of results by both synergies and interferences between the cations and anions, the potentially active moieties were tested separately with (reasonably assumed) benign counterions, $\mathrm{Na}^{+}, \mathrm{Cl}^{-}$, so that such behavior could be disentangled. The known reaction products of SDF, i.e., calcium fluoride and silver phosphate, logically should be tested on this basis, but, of course, they have very low solubility 
and so are not capable of a suitable solution. In any case, the only relevant ions are $\mathrm{Ag}^{+}$and $\mathrm{F}^{-}$, since calcium and phosphate are not expected to be inhibitory, and these are dealt with separately.

Amongst the large number of species of bacteria normally present in the oral flora, Streptococcus, Lactobacillus, and Actinomyces species have been reported to be associated with both dentin and root caries ${ }^{41-43}$ and to have been isolated from carious dentin using anaerobic techniques. ${ }^{44-46}$

Since $\mathrm{NH}_{4} \mathrm{Cl}$ had no $\mathrm{AB}$ effect at either concentration, it is clear that neither $\mathrm{NH}_{4}{ }^{+}$nor $\mathrm{Cl}^{-}$is $\mathrm{AB}$ as such, which was to be expected. Similar arguments show that none of $\mathrm{Na}^{+}, \mathrm{Cl}^{-}$, and $\mathrm{NO}_{3}{ }^{-}$is $\mathrm{AB}$, again as expected (gross osmotic effects excepted, although incidentally these results show that they are not significant here). $\mathrm{NaF}\left(\left[\mathrm{F}^{-}\right]=17,000 \mathrm{ppm}\right)$ was not $\mathrm{AB}$; however, $\mathrm{NH}_{4} \mathrm{~F}$ was only effective at high concentration $\left(\left[\mathrm{F}^{-}\right]=190,000 \mathrm{ppm}\right)$. Taken together, this implies that $\mathrm{F}^{-}$is $\mathrm{AB}$ at high concentration. This was confirmed by the dilution series test of $\mathrm{NH}_{4} \mathrm{~F}$ : cut-off points were 200 (L. acidophilus) and $100 \mathrm{mg} / \mathrm{mL}$ (Graph 1C). For the ADT of $\mathrm{NH}_{4} \mathrm{~F}$ at $400 \mathrm{mg} / \mathrm{mL}$, after 5 days of incubation all bacteria grew back into the former inhibition zone. This supports the concentration effect deduction as ion diffusion is continuous (in the absence of removal by binding or precipitation), while the indistinct edge of the inhibition zone indicates that $\mathrm{F}^{-}$is indeed a bacterial inhibitor rather than bactericidal under the present circumstances, as indicated elsewhere. ${ }^{47}$

$\mathrm{NH}_{4} \mathrm{~F}$ has not been widely used, presumably due to its toxicity and the pungency of the released $\mathrm{NH}_{3}$, and it has been little studied. Only Maltz and Emilson ${ }^{48}$ have investigated the susceptibility of oral bacteria to $\mathrm{NH}_{4} \mathrm{~F}$, along with $\mathrm{NaF}, \mathrm{SnF}_{2}$, and $\mathrm{CuF}_{2}$, concluding that fluoride has an $\mathrm{AB}$ effect only at high concentration. They also remarked that, for $\mathrm{SnF}_{2}$ and $\mathrm{CuF}_{2}$, the metal ions seem to play a major role, with both of which observations the present results are consistent.

Comparing the low-concentration results for $\mathrm{NaNO}_{3}$ and $\mathrm{NaF}$, which showed no $\mathrm{AB}$ effect, with those for $\mathrm{AgNO}_{3}$ and $\mathrm{AgF}$, which did, it is concluded that it is only the silver ions that are $\mathrm{AB}$.

The weaker $\mathrm{AB}$ effect of SDF at high concentration compared with $\mathrm{NH}_{4} \mathrm{~F}$ may be due to chloride in the agar precipitating silver ions. ${ }^{9}$ In addition, since there was no significant difference between the $\mathrm{AB}$ effects of $\mathrm{AgF}$ and
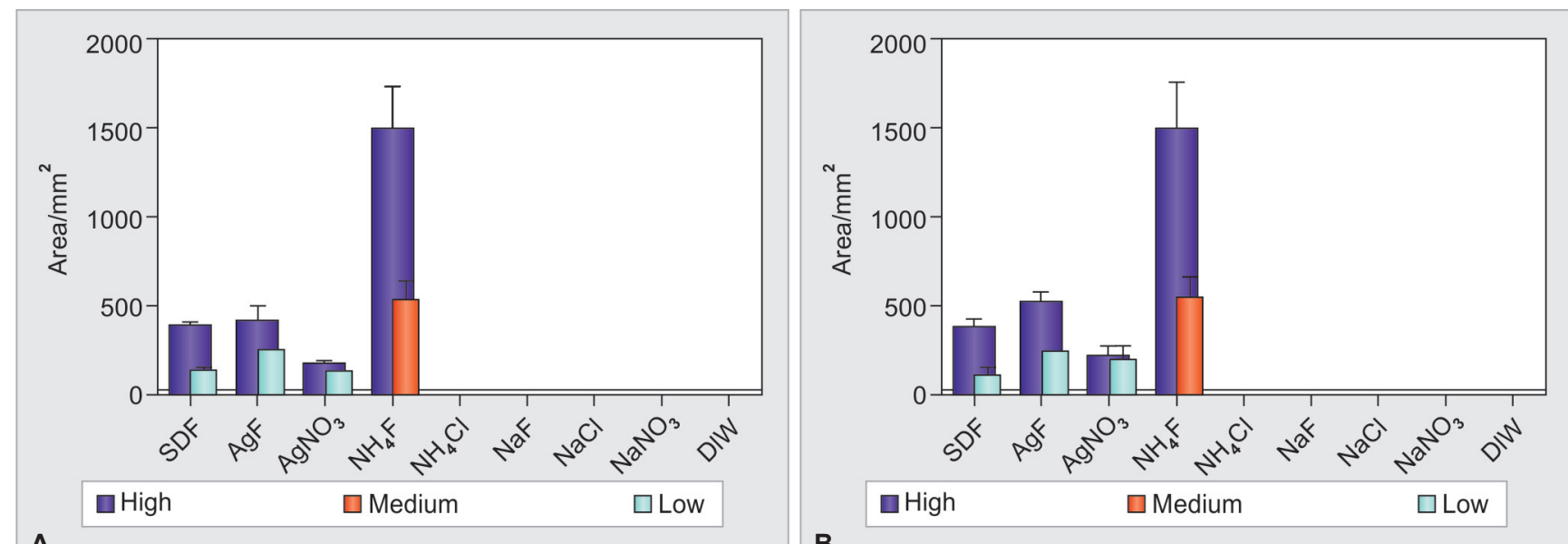

A

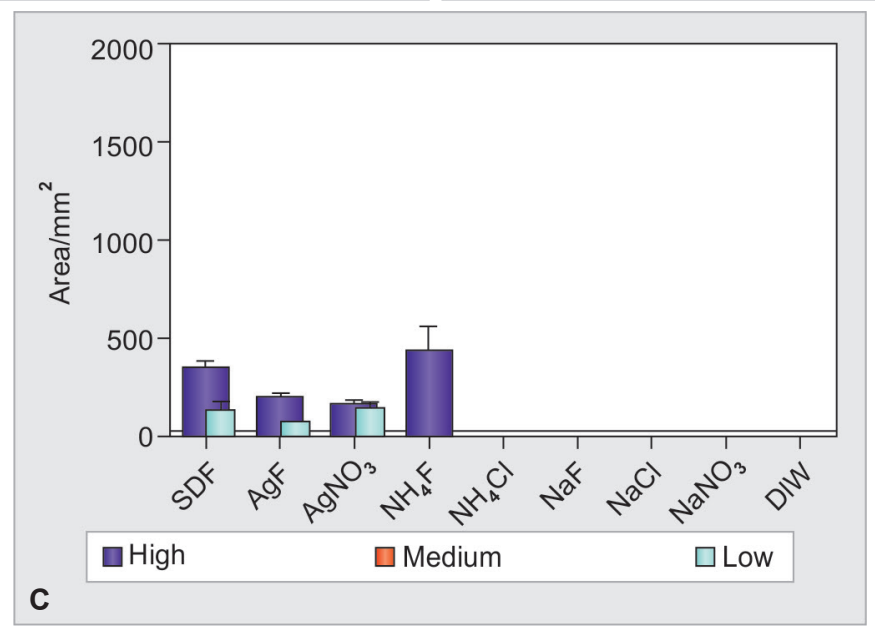

Graphs $1 \mathrm{~A}$ to $\mathrm{C}$ : Inhibition zone areas for the three test bacteria for the various test agents. Error bars: \pm 1 standard deviation "High" and "low" concentrations as in Table 1, "medium" $=200 \mathrm{mg} \mathrm{mL}^{-1}$ (A) S. mutans, (B) A. naes/undii, (C) L. acidophilus 
SDF, it would appear that the ammonium group in SDF (i.e., from the dissolved $\mathrm{NH}_{3}$ ) makes no contribution. That both SDF and AgF had a significantly better effect than $\mathrm{AgNO}_{3}$ at high concentration might possibly be due to the modest $\mathrm{AB}$ effect of fluoride (as seen above for $\mathrm{NH}_{4} \mathrm{~F}$ ) being additive, ${ }^{49-51}$ but this needs checking. However, this would not apply at low concentration where silver ion appears as the only $\mathrm{AB}$ entity.

Thus, it is deduced that of the tested systems, the principal $\mathrm{AB}$ entity is $\mathrm{Ag}^{+}$, although the $\mathrm{AB}$ efficacy of SDF, $\mathrm{AgF}$, and $\mathrm{AgNO}_{3}$ was not identical for the three species tested, suggesting some variation in agent sensitivity (although the ion concentrations were not controlled here, the results are not directly related to those values-see Table 1 and Graph 1), and also between species.

The AB mechanism of fluoride has been investigated widely through studies of the inhibition of adhesion ${ }^{52}$ and metabolism. ${ }^{53}$ Here, an effect was only seen at high concentration, consistent with the results of previous studies. Thus, Rickles and Becks ${ }^{54}$ found from $\mathrm{pH}$ and bacterial growth measurements that $2 \% \mathrm{NaF}$ did not alter the acidogenic properties of the oral flora in collected saliva, while Kilian et $\mathrm{al}^{55}$ reported no detectable difference in the flora of plaque samples from children exposed to high (21 ppm) and low (0.3 ppm) drinking water fluoride concentrations with which the present result is also consistent. However, from colony counting, $250 \mu \mathrm{g} / \mathrm{mL} \mathrm{NaF}$ (113 ppm F) has been reported to be the lowest concentration to inhibit streptococci but not Actinomycetaceae. ${ }^{56}$ For comparison, topical fluoride as a $1 \% \mathrm{NaF}(4,500 \mathrm{ppm} \mathrm{F})$ gel reduced the production of acetate and lactate in both noncancer and postirradiation xerostomic cancer patients, ${ }^{57}$ while even 0.5 ppm fluoride depressed acid production. ${ }^{58}$ It would seem essential to distinguish carefully between an outright $\mathrm{AB}$ effect and metabolic modification, which has not always been done.

Although an $\mathrm{AB}$ effect for fluoride itself has been reported by some, its actual role or mechanism as an $\mathrm{AB}$ agent in the mouth, never clear, ${ }^{59}$ is now greatly in doubt, ${ }^{60}$ but in any case, this question now seems to be generally overshadowed by studies of de- and remineralization. However, while the effectiveness of fluoride in remineralization has been debated, ${ }^{61}$ the current view is positive, ${ }^{62,63}$ albeit with no clear mechanism indicated. The critical point now is that the fluoride concentration needed for any AB effect in the ADT is plainly substantially greater than that needed to affect the solubility of apatite, and it is necessary to distinguish between the two kinds of mechanism, even if the outcome-interference with the progress of the carious process-is apparently the same and desirable.
In summary, at low concentration, the $A B$ effect of SDF is due only to silver ions. Fluoride inhibits bacteria at very high concentration $\left(\left[\mathrm{F}^{-}\right]>=97,000 \mathrm{ppm}\right)$, but no effect was found at $\left[\mathrm{F}^{-}\right]<49,000 \mathrm{ppm}$, and especially, there is no clear cooperative or synergistic action with silver ions. $\mathrm{NH}_{4}{ }^{+}, \mathrm{Na}^{+}, \mathrm{Cl}^{-}$, and $\mathrm{NO}_{3}{ }^{-}$had no detectable $\mathrm{AB}$ effect. The effect of $\mathrm{Ag}^{+}$in broth may be constrained by the chloride present.

These results must be put into the context of the biofilm of the oral environment. It is understood that agar-diffusion is only a screening test and that it cannot be used to determine the efficacy of a process in vivo. This arises simply because the biofilm itself has different properties, chemically and physically, while the community of organisms behaves differently to isolated species. ${ }^{64-66}$ This is well understood, and is the basis of the development of artificial mouth systems. ${ }^{64,65,67}$ However, in the present work, we are showing an absence of effect for fluoride (and other certain other chemical species) in a system that would be expected to show the greatest possible sensitivity. But, it is understood that the sensitivity of the organisms in a monospecific culture cannot be less than that in a biofilm ${ }^{64,65}$. It follows then that the screening test can be no worse, and is probably rather more sensitive, for detecting the possibility of an effect. Obviously, were there to be one, then a biofilm test would be required to confirm and assess sensitivity. Thus, we can conclude that, simplistic though it may be, the ADT suggests now that an $\mathrm{AB}$ effect for clinically relevant concentrations of fluoride in the context of a biofilm is unlikely. Equally, in the case of silver (whose efficacy has, as far as we know, never been challenged) in the context of a biofilm, some lesser effect might be encountered and that such a system would need to be studied. A distinction also needs to be drawn between the general exposure of biofilms to fluoride through mouth rinses, APF and the like, and the precisely targeted treatment of caries with silver solutions. Nevertheless, the lethality of $\mathrm{Ag}^{+}$should it contact the organism is confirmed, and this provides a good positive control for any more elaborate screening system. ${ }^{67}$

\section{CONCLUSION}

Consistent with the bulk of related observations and the expectations of the chemistry, it was concluded that it is silver ions that exert the principal $\mathrm{AB}$ effect in the compounds studied, so that if 'optimization' of SDF or the like as an anticaries agent is to be pursued, it should be with regard to the $A B$ effect of silver ions, the role of fluoride being complementary with respect to de- or remineralization, but not $\mathrm{AB}$ at the relevant concentrations. However, these are in vitro results and this needs to be confirmed 
in vivo or on more suitable tooth models. Further outcomes should examine how to conduct more elaborate trials involving dilution methods and biofilms over different time periods ultimately leading to clinical trials.

\section{CLINICAL SIGNIFICANCE}

Silver compounds, such as SDF, silver fluoride, and silver nitrate have $\mathrm{AB}$ effect against cariogenic organisms and these may have clinical impact in arresting or preventing dental decay. Sodium fluoride did not have AB effect under the conditions tested.

\section{REFERENCES}

1. Russell AD, Hugo WB. Antimicrobial activity and action of silver. Prog Med Chem 1994;31:351-370.

2. White RJ. An historical overview of the use of silver in wound management. Br J Nurs 2001;10(15):S3-S8.

3. Landsdown ABG. Silver in health care: antimicrobial effects and safety in use. Curr Probl Dermatol 2006;33:17-34.

4. Darouiche RO, Meade R, Mansouri M, Raad II. In vivo efficacy of antimicrobial-coated fabric from prosthetic heart valve sewing rings. J Heart Valve Dis 1998 Nov;7(6):639-646.

5. Darouiche RO. Anti-infective efficacy of silver-coated medical prostheses. Clin Infect Dis 1999 Dec;29:1371-1378.

6. Hipler C, Elsner P, Fluhr JW. New silver-coated cellulose fibres: in vitro investigations into antibacterial and antimycotic activity. The 2nd European Conference on Textiles and the Skin, Stuttgart, Germany; 2004:No 5-1-29.

7. Pyle BH, Broadaway SC, McFeters GA. Efficacy of copper and silver ions with iodine in the inactivation of Pseudomonas cepacia. J Appl Bacteriol 1992 Jan;72(1):71-79.

8. Coward JE, Carr HS, Rosenkranz HS. Silver sulfadiazine: effect on the ultrastructure of Pseudomonas aeruginosa. Antimicrob Agents Chemother 1973 May;3(5):621-624.

9. Richards RME. Antimicrobial action of silver nitrate. Microbios 1981;31(124):83-91.

10. Fox CL, Modak SM. Mechanism of silver sulphadiazine action on burn wound infections. Antimicrob Agents Chemother 1974 Jun;5(6):528-588.

11. Thurman RB, Gerba CP. The molecular mechanisms of copper and silver ion disinfection of bacteria and viruses. Crit Rev Environ Control 1988;18:295-315.

12. Fuhrmann GF, Rothstein A. The mechanism of the partial inhibition of fermentation in yeast by nickel ions. Biochim Biophys Acta 1968 Nov;163(3):331-338.

13. Bragg PD, Rainnie DJ. The effect of silver ions on the respiratory chain of Escherichia coli. Can J Microbiol 1974 Jun;20(6):883-889.

14. Gardner AF, Higel RW. An evaluation of agents used in cavity sterilization. Aust Dent J 1962 Feb;7(1):53-61.

15. Stebbins EA. What value has argenti nitras as therapeutic agent in dentistry? Int Dent J 1891;7:53-61.

16. Miller WD. Preventive treatment of the teeth, with special reference to silver nitrate. Dental Cosmos 1905;47:913-922.

17. Howe PR. A method of sterilizing, and at the same time impregnating with a metal, affected dentinal tissue. Dental Cosmos 1917;59:891-904.
18. Muntz JA, Dorfman A, Stephan RM. In vitro studies on sterilization of carious dentin. I. Evaluation of germicides. J Am Dent Assoc 1943 Dec;30(23):1893-1900.

19. Prime JM. Further extending use of Howe's ammoniacal silver nitrate in control of dental caries. Dental Cosmos 1935 Nov;77(11):1046-1059.

20. Prime JM. Preventive dentistry. J Am Dent Assoc 1940;27: 1213-1222.

21. Zander HA. Use of silver nitrate in the treatment of caries. J Am Dent Assoc 1941 Aug;28(8):1260-1267.

22. Zander HA, Burrill DY. Penetration of silver nitrate solution into dentin. J Dent Res 1943;22:85-87.

23. Englander HR, James VE, Massler M. Histologic effects of silver nitrate of human dentin and pulp. J Am Dent Assoc 1958 Nov;57(5):621-630.

24. Lansdown A, Williams A. Bacterial resistance to silver-based antibiotics. Nurs Times 2007 Feb-Mar;103(9):48-49.

25. Yamaga R, Yokomizo I. Arrestment of caries of deciduous teeth with diamine silver fluoride. Dent Outlook 1969;33:1007-1013.

26. Lou YL, Botelho MG, Darvell BW. Erratum to "Reaction of silver diamine fluoride with hydroxyapatite and protein" [J Dent 39 (2011) 612-618]. J Dent 2012;40:91-93.

27. Yamaga R, Nishino M, Yoshida S, Yokomizo I. Diamine silver fluoride and its clinical application. J Osaka Dent Univ 1972 Sep;12:1-20.

28. Suzuki K, Ohkubo T. Infected root canal treatment by $\mathrm{Ag}(\mathrm{NH} 3) 2 \mathrm{~F}$ solution-especially stump teeth treatment. Dent Outlook 1974;43:99-102.

29. Hori T, Kawamura K, Kajiwara T, Nagao K, Isoda K, Itsumi T. Effect of application of $3.8 \% \mathrm{Ag}\left(\mathrm{NH}_{3}\right)_{2} \mathrm{~F}$ solution as a disinfectant. Dent Outlook 1975;46:495-500.

30. Klein U, Kanellis MJ, Drake D. Effects of four anticaries agents on lesion depth progression in an in vitro caries model. Pediatr Dent 1999 May-Jun;21(3):176-180.

31. Llodra JC, Rodriguez A, Ferrer B, Menardia V, Ramos T, Morato M. Efficacy of silver diamine fluoride for caries reduction in primary teeth and first permanent molars of schoolchildren. 36-month clinical trial. J Dent Res 2005 Aug;84(8):721-724.

32. Chu CH, Lo ECM. Effectiveness of silver diamine fluoride and sodium fluoride varnish in arresting dentin caries in Chinese pre-school children. J Dent Res 2002;81:767-770.

33. Craig GG, Powell KR, Cooper MH. Caries progression in primary molars. 24-month results from a minimal treatment programme. Community Dent Oral Epidemiol 1981 Dec;9(6):260-265.

34. de Almeida LdFD, Cavalcanti YW, Valença AMG. In vitro antibacterial activity of silver diamine fluoride in different concentrations. Acta Odontol Latinoam 2011;24(2):127-131.

35. Lou YL, Botelho MG, Darvell BW. Reaction of silver diamine fluoride with hydroxyapatite and protein. J Dent 2011 Sep;39(9):612-618.

36. Tobias RS, Browne RM, Wilson CA. Antibacterial activity of dental restorative materials. Int Endod J 1985 Jul;18(3):161-171.

37. Balouiri M, Sadiki M, Koraichi Ibn Souda S. Methods for in vitro evaluating antimicrobial activity: a review. J Pharm Anal 2016 Apr;6(2):71-79.

38. Barry AL. Agar diffusion test. In: Barry AL, editor. The antimicrobial susceptibility test: principles and practices. Philadelphia, PA: Lea \& Febiger; 1976. pp. 163-213.

39. Tobias RS. Antibacterial properties of dental restorative materials: a review. Int Endod J 1988 Mar;21(2):155-160. 
40. Rolla G, Löe H, Schiott CR. The affinity of chlorhexidine for hydroxyapatite and salivary mucins. J Periodontal Res 1970;5(2):90-95.

41. de Soet JJ, Weerheijm KL, van Amerongen WE, de Graaff J. A comparison of the microbial flora in carious dentine of clinically detectable and undetectable occlusal lesions. Caries Res 1995;29(1):46-49.

42. Hahn C-L, Falkler WA, Minah GE. Microbiological studies of carious dentine from human teeth with irreversible pulpitis. Arch Oral Biol 1991;36(2):147-153.

43. Hoshino E. Predominant obligate anaerobes in human carious dentin. J Dent Res 1985 Oct;64(10):1195-1198.

44. Edwardsson S. Bacteriological studies on deep areas of carious dentine. Odontol Revy 1974;32:1-143.

45. Emilson CG. Potential efficacy of chlorhexidine against mutans streptococci and human dental caries. J Dent Res 1994 Mar;73(3):682-691.

46. GibbonsRJ,SocranskySS,SawyerS,Kapsimalis B,MacdonaldJB. The microbiota of the gingival crevice area of man. II. The predominant cultivable organisms. Arch Oral Biol 1963 May-Jun;8:281-289.

47. Bradshaw DJ, Marsh PD, Hodgson RJ, Visser JM. Effects of glucose and fluoride on competition and metabolism within in vitro dental bacterial communities and biofilms. Caries Res 2002 Mar-Apr;36(2):81-86.

48. Maltz M, Emilson CG. Susceptibility of oral bacteria to various fluoride salts. J Dent Res 1982 Jun;61(6):786-790.

49. Gotjamanos T, Afonso F. Unacceptably high levels of fluoride in commercial preparations of silver fluoride. Aust Dent J 1997 Feb;42(1):52-53.

50. Gotjamanos T, Orton V. Abnormally high fluoride levels in commercial preparations of 40 percent silver fluoride solution: contraindications for use in children. Aust Dent J 1998;43(6):422-427.

51. Gotjamanos T, Orton V. Fluoride ion concentration in 40 per cent silver fluoride solutions determined by ion selective electrode and ion chromatography techniques. Aust Dent J 1998 Feb;43(1):55-56.

52. Kilian M, Larsen MJ, Fejerskov O, Thylstrup A. Effects of fluoride on the initial colonization of teeth in vivo. Caries Res 1979;13(6):319-329.

53. Hamilton IR. Effects of fluoride on enzymatic regulation of bacterial carbohydrate metabolism. Caries Res 1977;11 (Suppl 1): 262-291.
54. Rickles NH, Becks H. The effect of topical applications of sodium fluoride on the oral flora of young adults. J Dent Res 1952 Feb;31(1):94-101.

55. Kilian M, Thylstrup A, Fejerskov O. Predominant plaque flora of Tanzanian children exposed to high and low water fluoride concentrations. Caries Res 1979;13(6):330-343.

56. Beighton D, McDougall WA. The effects of fluoride on the percentage bacterial composition of dental plaque, on caries incidence, and on the in vitro growth of Streptococcus mutans, Actinomyces viscosus, and Actinobacillus sp. J Dent Res 1977 Oct;56(10):1185-1191.

57. Brown LR, White JO, Horton IM, Dreizen S, Streckfuss JL. Effect of continuous fluoride gel use on plaque fluoride retention and microbial activity. J Dent Res 1983 Jun;62(6):746-751.

58. Wright DE, Jenkins GN. The effect of fluoride on the acid production of saliva-glucose mixtures. Br Dent J 1954;96:30-33.

59. Bowden GH, Hamilton IR. Competition between Streptococcus mutans and Lactobacillus casei in mixed continuous culture. Oral Microbiol Immunol 1989 Jun;4(2):57-64.

60. Clincha C. Does dental fluoride use have clinically significant effects on oral bacteria? Fluoride 2010;43:205-214

61. Tatevossian A. Fluoride in dental plaque and its effects. J Dent Res 1990 Feb;69 Spec No:645-652, 682-683.

62. Lynch RJM, Mony JM, ten Cate JM. The effect of fluoride at plaque fluid concentrations on enamel de- and remineralisation at low pH. Caries Res 2006;40(6):522-529.

63. Lynch RJM, Navada R, Walia R. Low-levels of fluoride in plaque and saliva and their effects on the demineralisation and remineralisation of enamel; role of fluoride toothpastes. Int Dent J 2004;54(5 Suppl 1):304-309.

64. Marsh PD. The role of microbiology in models of dental caries. Adv Dent Res 1995 Nov;9(3):244-254, 255-269.

65. Marsh PD. Dental plaque: biological significance of a biofilm and community life-style. J Clin Periodontol 2005;32 (Suppl 6): 7-15.

66. Sissons CH, Cutress TW, Hoffman MP, Wakefield JS. A multistation dental plaque microcosm (artificial mouth) for the study of plaque growth, metabolism, $\mathrm{pH}$, and mineralization. J Dent Res 1991 Nov;70(11):1409-1416.

67. Donoghue HD, Perrons CJ, Hudson DE. The role of $\mathrm{H}_{2} \mathrm{O}_{2}$ and the lactoperoxidase- $\mathrm{SCN}-\mathrm{H}_{2} \mathrm{O}_{2}$ system on the interaction between two bacteria originating from human dental plaque, Streptococcus rattus (mutans) BHT and Streptococcus mitior LPA-1, grown on human teeth in an artificial mouth. Arch Oral Biol 1985;30(7):519-523. 